\title{
Diretrizes básicas para criação de uma agencia reguladora nuclear
}

\author{
Sandra Regina Cabidolusso Lavalle Heilbron ${ }^{1,2}$, Stella Regina Reis da Costa ${ }^{2}$ \\ \sandra@cnen.gov.br
}

1. Comissão Nacional de Energia Nuclear - CNEN, Rua Gen. Severiano, 90, Rio de Janeiro, Brasil.
2. Universidade Federal Fluminense, Rua Passo da Pátria, 156, Niterói, Brasil.

\section{Histórico do Artigo:}

Recebido: 20 de abril de 2016

Aceito: 21 de junho de 2017

Publicado: 5 de janeiro de 2018

\begin{abstract}
Resumo: Na década de 50 foi criada a Comissão Nacional de Energia Nuclear (CNEN), uma Autarquia Federal que, desmembrada do Conselho Nacional de Desenvolvimento Científico e Tecnológico (CNPq), surgiu com os objetivos principais de desenvolver a energia nuclear e suas aplicações, bem como controlar a área nuclear do país, garantindo a sua segurança. A importância da criação de uma agência regulatória independente para o setor nuclear, ou seja, a separação das atividades da CNEN relativas à segurança das atividades voltadas ao desenvolvimento e pesquisa básica não regulatória é muito antiga e sempre foi um tema debatido pela comunidade científica. Atualmente, este tema ganhou novamente força e iniciou-se a elaboração de uma minuta de projeto de Lei para a criação de uma agência reguladora independente do setor nuclear, em avaliação no Ministério de Ciência, Tecnologia, Inovações e Comunicações (MCTIC). 0 objetivo deste trabalho é apresentar diretrizes para a criação de uma agência reguladora do setor nuclear,realizando uma pesquisa metodológica através do uso de questionário e pesquisa aplicada, uma vez que pretende-se resolver um problema real em uma instituição que acumula funções de segurança com funções de desenvolvimento tecnológico, o que na prática, deveriam ser separadas. Assim, aplicou-se questionáriosjunto aos gestores e ex gestores da CNEN, comquestões relacionadas à construção de uma agência reguladora, procedimento que ajudou a completar o conjunto de diretrizes propostas. Como resultado deste trabalho, são apresentadas dezesseis recomendações/diretrizes para a criação de uma agência nuclear no Brasil.
\end{abstract}

Palavras-chave: Agência reguladora, Independência, Setor nuclear, Diretrizes, CNEN.

\section{Basic guidelines for the creation of a nuclear regulatory agency}

\begin{abstract}
In the 1950s, the Brazilian Nuclear Energy Commission (CNEN) was created, a Federal Autonomy that, dismembered by Brazilian National Council of Scientific and Technological Development (CNPq), emerged with the main objectives of developing nuclear energy and its applications, as well as controlling the nuclear area of the country, ensuring their safety. The importance of setting up an independent regulatory agency for the nuclear sector, ie the separation of CNEN activities focused on the safety of development activities and basic non-regulatory research is very old and has always been a topic debated by the scientific community. This issue has again gained momentum and a draft Bill for the creation of an independent regulatory agency for the nuclear sector has been drafted and is being evaluated by the Ministry of Science, Technology, Innovation and Communications (MCTIC). The objective of this work was to present guidelines for the creation of a regulatory agency of the nuclear sector performing a methodological research through the use of a questionnaire and applied research since it intends to solve a real problem in an institution that accumulates security functions with functions of technological development that in practice should be separated as previously pointed out. These guidelines are presented at the end of the paper. A questionnaire distributed to CNEN managers and former managers was used, containing questions related to a regulatory agency that helped complete the set of proposed guidelines. As a result of this work, sixteen recommendations / main guidelines are presented for the creation of a nuclear agency in Brazil.
\end{abstract}

Keywords: Agency, Independence, Nuclear Sector, Guidelines, CNEN. 


\section{Directrices básicas para la creación de una agencia de regulacion nuclear}

Resumen: Em los años 50 se crêó la Comisión Nacional de Energía Nuclear (CNEN) una agencia gubernamental que se escindió de la Consejo Nacional de Desarrollo Científico y Tecnológico (CNPq), surgió com el objetivo principal de desarrollar la energía nuclear y sus aplicaciones, así como controlar el área nuclear del país, asegurando su seguridad. la importancia de la creación de un organismo regulador independiente para el sector nuclear, es decir, la separación de lãs actividades CNEN que se centra nen lãs actividades de seguridad orientadas al desarrolloen lugar de la investigación básica reguladora es muy antigua y siempre ha sido un tema discutido por la comunidad científica. Actualmente este tema una vez más ganó fuerza y comenzó la elaboración de um proyecto de proyecto de ley para la creación de un regulador independiente de la industria nuclear, que se encuentra em evaluación em el Ministerio de Ciencia, Tecnología, Innovación y Comunicaciones (MCTIC). El objetivo de este estudio es presentar directrices para la creación de un organismo regulador de la industria nuclear realizando una investigación metodológica por el uso de um cuestionario y una investigación aplicada una vez que se resuelveun problema real en una organización que acumula Funciones de seguridad con funciones de desarrollo tecnológico que em la práctica de ben ser separados como apontado anteriormente. Estas directrices se presentan al final Del trabajo. Se utilizo um cuestionario distribuido a los directivos y ex gerentes CNEN contiene preguntas relacionadas con una agencia reguladora que ayudó a completar el conjunto de directrices propuestas. Como resultado de este trabajo se presentan diecisiete recomendaciones/ directrices principales para la creación de una agencia nuclear en Brasil.

Palabras clave: Autoridad reguladora, autoridadindependiente, laindustria nuclear, Directrices, la CNEN.

\section{INTRODUÇÃO}

\section{Origem das Agências Reguladoras}

Barroso (1999) observou que as funções transferidas para as agências reguladoras não são novas. Em sua visão, o Estado sempre teve o encargo de zelar pela boa prestação dos serviços. Todavia, quando eles eram prestados diretamente pelo próprio Estado ou indiretamente por pessoas jurídicas por ele controladas (como as sociedades de economia mista e as empresas públicas), estas funções não tinham visibilidade e não eram eficientemente desempenhadas.

Clark (2007) explicitou que, durante a Guerra Fria, imperaram na economia de mercado as políticas econômicas neoliberais de regulamentação, onde o Estado Nacional transfigurouse em social, realizando a sua atuação no domínio econômico diretamente, via empresa pública, sociedade de economia mista e fundações; e indiretamente, através das normas legais de direito. Tudo em nome do desenvolvimento ou do crescimento.

Cruz (2012) analisou que nessa época de regulamentação, o capital privado era investido principalmente na indústria de consumo e na indústria armamentista, razão pela qual o poder econômico privado nacional e internacional necessitava da atuação estatal nos setores que apresentavam baixa lucratividade, riscos financeiros ou que eram carentes de 
investimentos tecnológicos, como as áreas social (educação, saúde e previdência) e de infraestrutura (energia, sistema viário, saneamento, telefonia), no sentido de viabilizar 0 progresso da economia de mercado, com a repressão aos movimentos sociais reivindicatórios (como dos trabalhadores) e a remoção do fantasma do socialismo. Com o novo ambiente mundial estabelecido a partir do fim da Guerra Fria, com a queda do socialismo real e com a evolução tecnológica, sobretudo na transição do século XX para o século XXI, surgiram novas pressões por parte dos donos do capital, que clamavam por outras políticas econômicas, as quais as políticas neoliberais de regulamentação não conseguiam atender, pois restringiam a expansão e mobilidade do capital. Nesta perspectiva, os Estados Nacionais passaram a executar o chamado neoliberalismo de regulação, transferindo serviços e atividades à iniciativa privada, por meio de privatizações e desestatizações, os quais, em razão da redução dos ganhos com a indústria bélica pelo fim da Guerra Fria e também dos avanços científicos, passaram a ser atraentes para os detentores do capital, onde o progresso tecnológico tornou lucrativos setores que antes ou não tinham, ou apresentavam baixa lucratividade e estavam nas mãos do Estado.

Cruz (2012) também observou que no processo de transformação do Estado ocorreu a desestatização de parte da prestação de serviços públicos, sobretudo nos setores de telecomunicações e energia elétrica, bem como a flexibilização do monopólio do petróleo. Essa nova configuração do Estado pressupôs, além da participação privada na prestação dos serviços públicos, a separação das tarefas de regulação das de exploração de atividades econômicas; orientar sua intervenção para a defesa do interesse público; buscar o equilíbrio nas relações de consumo no setor regulado, envolvendo usuários ou consumidores e prestadores de serviços; e exercitar a autoridade estatal por mecanismos transparentes e participativos.

De acordo com Clark (2007), o Estado passou a adotar o neoliberalismo de regulação como uma técnica de atuação na ordem econômica. 0 poder estatal continuou a intervir indiretamente no domínio da economia por meio das normas legais (leis, decretos, portarias, etc.), mas passou a intervir também de maneira intermediária, por meio das agências de regulação. Entretanto, essas agências atuam diferentemente das empresas estatais, pois não produzem bens nem prestam serviços à população, apenas fiscalizam e regulam o mercado ditando, por exemplo, comandos técnicos de expansão, qualidade, índices de reajuste de preços. A intervenção direta continua existindo nesse novo panorama regulatório e seguem 
existindo algumas empresas estatais no âmbito do mercado, mas em menor número e sem desempenhar o papel anterior, possuindo, na atualidade, reduzida capacidade de ingerência na vida econômica.

Analisando o contexto histórico sobre o papel do Estado, Dias (2010) considerou que a ausência da intervenção estatal na economia, característica principal do Estado Liberal, provocou o alargamento das desigualdades sociais, onde eram garantidos apenas os direitos básicos para a sobrevivência da população. Quando o Estado passou a intervir diretamente na economia, monopolizando os bens de produção e explorando diretamente os serviços públicos, ocorreu um engessamento no desenvolvimento econômico, sobretudo pela sua forte característica burocrática e o fato dele não ser suficientemente ágil e eficiente para acompanhar o desenvolvimento social. Posteriormente, com o surgimento de um novo modelo de Estado - o neoliberalismo, efetuou-se a intervenção nas atividades econômicas em prol do desenvolvimento e bem-estar social, onde o Estado criou mecanismos no sentido de regular os 31 setores econômicos e fomentar a produção de bens e serviços públicos, garantindo a sua universalização a custo acessível para a sociedade. É a partir deste momento que surgem no Brasil as Agências Reguladoras, desempenhando a função de intervenção estatal na economia, regulando, controlando e fiscalizando os setores estratégicos que o Estado delega à iniciativa privada.

Em termos legais, a Constituição Federal de 1988 (Brasil, 1988) recomendou o princípio da livre iniciativa.Contudo, delineou diretrizes visando a regulação de setores estratégicos passíveis de delegação, com a criação de órgãos reguladores em dois setores econômicos específicos: telecomunicações e petróleo; conforme consta nos art. 21, XI e art. 177, § 2º III, o que reforça a diretriz constitucional do Estado regulador.

Entretanto, o que alavancou a criação das agências foi a instituição do Plano Nacional de Desestatização (PND), em 1990, no qual ficou estabelecido que diversos setores estratégicos da economia seriam privatizados, o que determinou a necessidade da criação de órgãos de regulação e fiscalização.

A atividade regulatória estatal, no entanto, não é de exclusividade apenas das agências reguladoras, tendo outros órgãos no exercício de tais funções, entre os quais é destacado: 
- 0 Conselho Administrativo de Defesa Econômica (CADE), que atua em defesa da concorrência dos diferentes setores econômicos;

- A Comissão de Valores Mobiliários (CVM), que regula os mercados de capitais;

- $\quad$ C Conselho Monetário Nacional (CMN), que regula o sistema financeiro nacional;

- A Superintendência de Seguros Privados (SUSEP), que regula as seguradoras privadas; entre outros.

Na visão de Pacheco (2006), a criação das agências reguladoras deriva da política de reforma do Estado, iniciada em 1995, quando o Governo Federal, por meio do Ministro Luiz Carlos Bresser Pereira, juntamente com a equipe do recém criado Ministério da Administração Federal e Reforma do Estado (MARE), elaborou um amplo programa de reformas visando a descentralização da prestação de serviços públicos para esferas subnacionais e para o setor público não estatal e ao fortalecimento do núcleo estratégico do Estado, responsável pela formulação das políticas públicas e pelas novas funções de regulação.

Neste sentido, Brasil (1995) ressaltou que a reforma do Estado deve ser entendida dentro do contexto da redefinição do seu papel, que deixa de ser o responsável direto pelo desenvolvimento econômico e social pela via da produção de bens e serviços, para fortalecerse na função de promotor e regulador desse desenvolvimento. Tem se buscado o fortalecimento das funções de regulação e de coordenação do Estado, particularmente no nível federal, e a progressiva descentralização vertical, para os níveis estadual e municipal, das funções executivas no campo da prestação de serviços sociais e infraestrutura.

É nesse contexto, segundo Mesquita (2008), que surgem as agências reguladoras, órgãos criados por leis específicas na condição de Autarquias ditas especiais, dotadas de autonomia administrativa, financeira e patrimonial um pouco mais amplas do que as demais Autarquias.

Com o processo de privatização, conforme destacou Nunes (2007), sobreveio a necessidade de garantir a salvaguarda de determinados serviços públicos, e também, impor às empresas privadas prestadoras de serviços públicos um conjunto de obrigações próprias de um verdadeiro serviço público. Essa tarefa foi atribuída às entidades reguladoras independentes por se entender que "o Estado (o Estado Democrático), declarado, quase sempre por puro preconceito ideológico, incapaz de administrar o setor público da economia, é 
também considerado incapaz de exercer bem esta função reguladora”. A ideia de que era preciso regular os setores privatizados foi defendida porque, segundo várias correntes políticas, quando o mercado é deixado a si próprio, não protege "inteiramente o interesse público, não garante os objetivos públicos indispensáveis a um funcionamento 'organizado' do capitalismo e à 'paz social' capaz de viabilizar o funcionamento do sistema no respeito pelas regras da vida democrática".

Assim, as agências reguladoras são órgãos criados pelo governo para regular e fiscalizar os serviços prestados por empresas privadas que atuam na prestação de serviços, os quais em sua essência seriam públicos. Inspiradas na experiência internacional, foram criadas a partir de 1995, como entes públicos dotados de independência em relação ao Poder Executivo. Como esses serviços são de relevante valor social e, primordialmente, cabia ao Estado seu fornecimento, sua fiscalização deve ser feita por meio de algum órgão que se manifeste imparcial em relação aos interesses do Estado, da concessionária e dos consumidores.

\section{Agências Reguladoras no contexto das Reformas do Aparelho de Estado}

As agências reguladoras, de acordo com Fé (2003), fazem parte da chamada Reforma do Estado. A necessidade desta reforma tornou-se clara quando a organização do Estado, em especial os setores da administração pública vinculados ao Poder Executivo, passou a mostrarse incapaz de responder às demandas, tanto de indivíduos quanto de empresas, num mundo em constante transformação e sob a égide do capitalismo globalizado. Bresser Pereira (1997) observou que esta incapacidade teria como causa os problemas enfrentados pelos Estados Nacionais contemporâneos, sobretudo das nações subdesenvolvidas, tendo como principais: a crise fiscal, o modo de intervenção estatal e o modelo burocrático de gestão do Estado.

Nesta perspectiva, a Regulação aparece como ponto crucial no novo papel destinado ao Estado, como preconizado pela reforma do aparelho de Estado no Brasil.

Na visão de Fé (2003), as Agências reguladoras encontram-se enquadradas nas Atividades Exclusivas de Estado, pois estão diretamente relacionadas à questão do poder extroverso do Estado, tais como regulação, fiscalização e controle de atividades que, sendo ofertantes de bens públicos, implicam diretamente no nível de bem-estar da população. 
No entendimento de Nunes (2007), as organizações (agências reguladoras) que integram a administração pública são entidades de caráter híbrido, pois incorporam funções executivas, legislativas e judiciárias, como se constituíssem um quarto poder.

[...]às agências competem funções do executivo tais como a concessão e fiscalização de atividades e direitos econômicos. A elas estão atribuídas funções de legislativo, como a criação de normas, regras e procedimentos, com força legal sob sua área de jurisdição. Ao julgar, impor penalidades, interpretar contratos e obrigações, as agências desempenham, também, funções judiciárias.

Agências reguladoras constituem-se, por excelência, num lócus privilegiado de negociação entre diversos atores sociais e econômicos que se relacionam diretamente e que, muitas vezes, apresentam interesses divergentes.

Do ponto de vista de Peci \& Cavalcanti (2000) e Araújo \& Pires (2001), no intuito de que as agências pudessem desempenhar com eficácia o papel para o qual foram criadas, a legislação que as instituiu estabeleceu critérios que garantissem sua autonomia decisória:

a) Autonomia Decisória e Financeira: natureza jurídica de autarquia especial com orçamento próprio;

b) Estabilidade: mandato fixo para a diretoria e critério rígido de exoneração dos diretores;

c) Transparência: mandatos não coincidentes e a presença, em suas estruturas organizacionais, de ouvidoria, conselho consultivo e a realização de audiências e consultas públicas;

d) Especialização: quadro técnico especializado;

e) Cooperação Institucional: atuação em cooperação com o CADE e órgãos de defesa do consumidor.

\section{Importância da criação de uma Agência Reguladora Nuclear}


A importância de se criar uma agência regulatória independente para o setor nuclear, implementando a separação das atividades voltadas à segurança das operações de desenvolvimento e pesquisa básica/aplicada não regulatória de atribuição da CNEN é muito antiga e sempre foi um tema que suscitou discussões.

Uma das principais críticas à criação de agências reguladoras no Brasil justifica que, em geral, elas são subordinadas diretamente aos Ministérios do Executivo, o que torna suas decisões passíveis de revisão, por pressão dos ministros, o que ocorreria no caso de uma agência reguladora do setor nuclear fosse subordinada ao MCTIC,como é o caso da CNEN hoje em dia e a INB,que é subordinada ao Ministério de Minas e Energia (MME), considerando que o presidente da CNEN é atualmente o presidente do conselho de administração da INB (figura 1).

Segundo o Relatório do Grupo de Trabalho, Fiscalização e Segurança Nuclear, da Consultoria Legislativa da Câmara (Brasil, 2006), a atual estrutura da CNEN não reflete, em termos real, a independência do órgão regulador, uma vez que acumula atividades de segurança e desenvolvimento tecnológico. A Convenção de Segurança Nuclear, promulgada pelo Congresso Nacional (Brasil,1998), em seu artigo oitavo,estabelece que cada um dos países signatários deverá: “Tomar medidas apropriadas para assegurar uma efetiva separação entre as funções do órgão regulador e aquelas de qualquer outro órgão ou organização relacionado com a promoção ou utilização da energia nuclear".

Uma questão de desrespeito a essa premissa de independência, apontada no relatório da Câmara, é a situação da INB (antiga NUCLEBRAS - Empresas Nucleares Brasileiras S/A), que apesar de pertencer à estrutura da CNEN, é responsável pelo ciclo do combustível, cujo objetivo é minerar, concentrar, converter em $\mathrm{UF}_{6}$ (hexa fluoreto de Urânio), reconverter, fazer pastilhas, produzir elementos combustíveis para as Usinas Angra 1, Angra 2 e futuramente Angra 3, fazendo assim com que a CNEN atue ao mesmo tempo como órgão licenciador desta empresa e presidente do conselho de administração da mesma. 


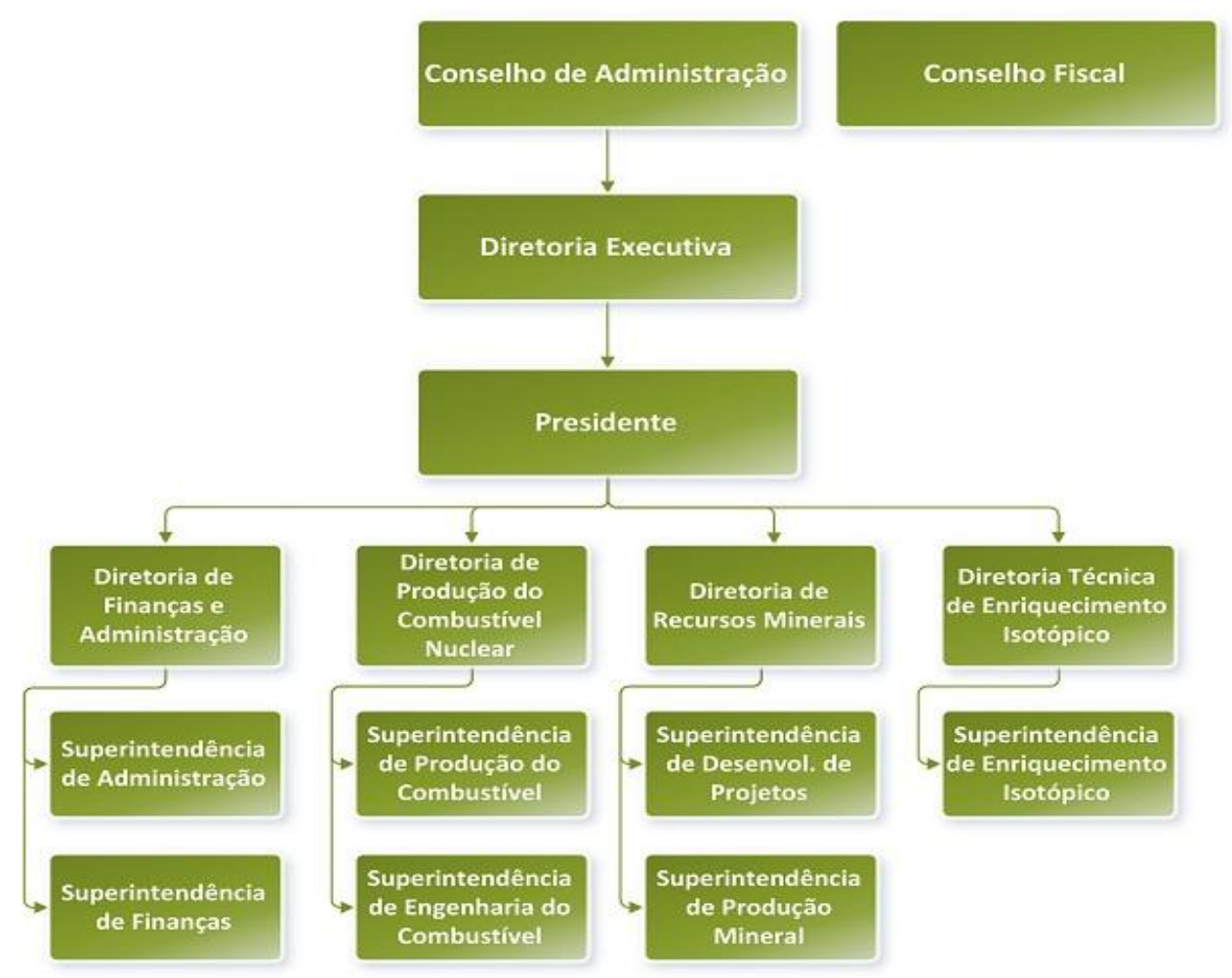

Figura 1. Estrutura da INB.

Fonte: INB (2015).

Outro exemplo que desconsidera a filosofia da Convenção de Segurança da IAEA, apontado pela Associação dos Fiscais de Radioproteção e Segurança Nuclear (AFEN) e que consta do relatório da Câmara supracitado, está no fato da CNEN atuar ao mesmo tempo como licenciadora e fiscalizadora de instalações nucleares de sua propriedade (como os reatores de pesquisa e os depósitos de rejeitos de seus institutos, etc.), sendo que alguns laboratórios pertencentes à CNEN ainda prestam serviços à INB e ELETRONUCLEAR, responsáveis respectivamente pelo ciclo do combustível e pela construção e operação das centrais nucleares brasileiras. 0utro exemplo de desrespeito à Convenção de Segurança é o caso da contratação da FUNDEP/CDTN/CNEN (Fundação de Desenvolvimento da Pesquisa/Centro de Desenvolvimento da Tecnologia Nuclear) para proceder à análise de acidentes postulados para a Fábrica de elementos combustíveis da INB/CNEN (Brasil, 2006), análise verificada e avaliada pela própria CNEN como pré-requisito para concessão da autorização de funcionamentoda Fábrica, ou seja, um instituto da CNEN prestando serviço para o operador que é fiscalizado pela própria CNEN. Em suma, a CNEN atua ao mesmo tempo como Requerente, Operadora, Prestadora de Serviços, Licenciadora e Fiscalizadora dela mesma. 
Outra observação relacionada à filosofia da Convenção de Segurança Nuclear se identifica para o caso das instalações nucleares existentes nos institutos de pesquisa da CNEN serem operados por ela própria. Além da inviabilidade de fiscalizá-las com a devida e necessária independência, surge o problema de como proceder para licenciá-las. A direção da CNEN, em 1994, optou por um processo de “autocertificação” dos seus institutos de pesquisa.

Os achados e recomendações do grupo de trabalho da Câmara constam do capítulo 5 do Relatório (Brasil, 2006), o qual aponta entre os principais problemas da CNEN, a sua atuação como "Fiscal de si mesma e a sua atuação questionável, ou seja, a face condescendente do órgão com os operadores".(sic)

A atual estrutura da CNEN, conforme mostra a Figura 2, evidencia os aspectos supracitados, isto é, que a instituição é fiscal de si mesma, apesar da existência de duas diretorias "independentes”: Diretoria de Radioproteção e Segurança Nuclear (DRS) e Diretoria de Pesquisa e Desenvolvimento (DPD).

\section{MATERIAL E MÉTODOS}

De maneira a elaborar quais seriam as principais diretrizes para a criação de uma agência reguladora do setor nuclear, foi realizada uma pesquisa junto aos gestores e exgestores da CNEN.

A pesquisa realizada para fins restritos a este trabalho foi dividida em duas partes, razão da elaboração de dois tipos diferentes de questionários distribuídos para os gerentes e ex-gerentes da CNEN. 0 primeiro questionário, com perguntas diretas, tenta identificar alguns pontos de interesse para a criação de uma agência reguladora;e o segundo questionário lista aspectos regulatórios, com o objetivo de identificar os pontos fracos e fortes sobre a CNEN atualmente, apontados por servidores que ocuparam e/ou ocupam cargos na Instituição, de maneira a identificar as principais diretrizes que podem contribuir para o funcionamento no Brasil de uma agência reguladora do setor nuclear que seja transparente, independente e eficiente.

0s questionários foram enviados para 50 gestores e ex-gestores, considerando aqueles com maior tempo de permanência no cargo. Do total de 50, 32 retornaram os questionários 
preenchidos, sendo 29 pós-graduados e 3 com nível superior,entre os quais 23 servidores possuem mais de 30 anos de experiência na área e 9 servidores são mais novos, contabilizando9 anos de experiência.

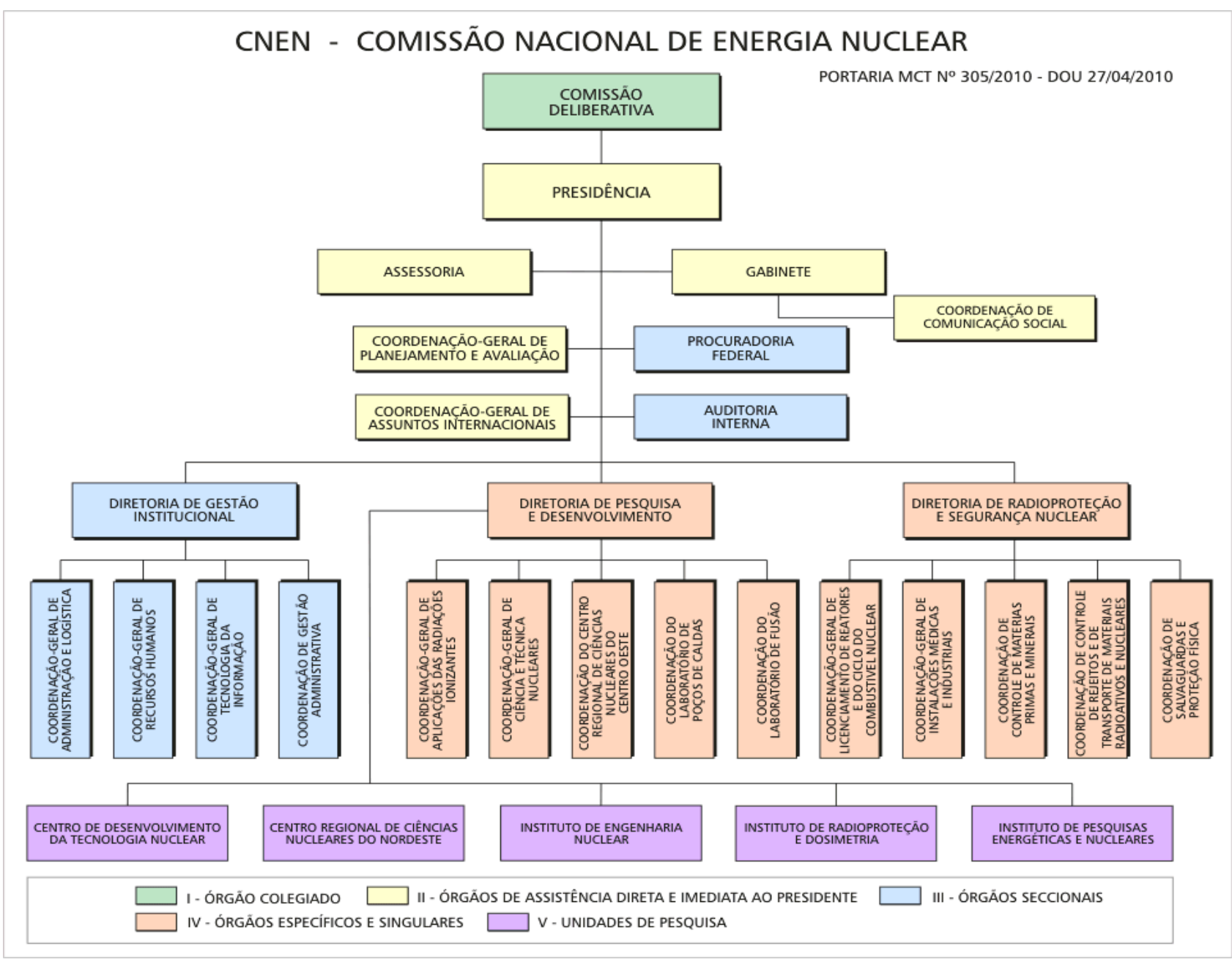

Figura 2. Estrutura atual da CNEN-2015.

Fonte: CNEN (2016).

Na primeira parte, foram feitas 20 perguntas diretamente relacionadas à uma agência reguladora, baseando-se nos pontos mais discutidos no dia a dia pelos servidores da CNEN, conforme mostra o quadro 1. 
Quadro 1 - Primeira parte do questionário aplicado.

1. 0 senhor/senhora tem conhecimento do que é uma agência reguladora?

2. 0 senhor/senhora concorda com a criação de uma agência reguladora?

3. Se o senhor/senhora concorda com a criação de uma agência reguladora, em que órgão deve estar subordinada a mesma? MCTIC, Casa Civil, outro órgão ou não importa?

4. 0 senhor/senhora acha que a área de segurança da CNEN é independente do operador, mesmo não sendo ainda uma agência reguladora?

5. 0 senhor/senhora participou do projeto de agência reguladora feito pela CNEN?

6. Se o senhor/senhora disse não à pergunta anterior, o senhor/senhora gostaria de ter participado no projeto de criação da agência reguladora?

7. Assinale quais fatores (tempo de experiência, titulação, seleção por escolha por votação direta, número de pareceres técnicos emitidos na área, número de fiscalizações realizadas, rigidez na concessão de autorizações) 0 senhor/senhora consideram importantes para a ocupação de cargos na agência reguladora?

8. 0 senhor/senhora acredita que deva haver critérios claros para ocupação de cargos em uma futura agência reguladora?

9. 0 senhor/senhora acredita que que deva existir limitação do tempo de permanência em cargos de chefia de uma agência reguladora?

10. Qual o tempo máximo (2, 3, 4,5 ou 7 anos) que o senhor/senhora recomenda para a ocupação nos cargos de Chefe de Divisão ou equivalente?

11. Qual o tempo máximo (2, 3, 4,5 ou 7 anos) que o senhor/senhora recomenda para a ocupação nos cargos de Chefe de Departamento ou equivalente?

12. Qual o tempo máximo (2, 3, 4,5 ou 7 anos) que o senhor/senhora recomenda para a ocupação nos cargos de Coordenador Geral ou equivalente?

13. Qual o tempo máximo $(2,3,4,5$ ou 7 anos) que o senhor/senhora recomenda para a ocupação nos cargos de Diretor?

14. 0 senhor/senhora acha correto que o servidor possa ser nomeado chefe de departamento sem antes ter ocupado a chefia de uma divisão?

15. 0 senhor/senhora acha que deve haver critérios para progressão nos cargos na agência reguladora?

16. 0 senhor/senhora sabe o que significa pesquisa regulatória?

17. 0 senhor/senhora sabe da Importância da pesquisa regulatória para uma agência reguladora?

18. 0 senhor/senhora considera necessário que uma agência reguladora possua um laboratório independente em sua estrutura?

19. 0 senhor/senhora considera importante a existência de uma ouvidoria na agência reguladora?

20. 0 senhor/senhora considera importante a participação de membros representantes das associações na ouvidoria?

Fonte: Própria.

\section{RESULTADOS E DISCUSSÃO}

A análise da primeira parte do questionário permitiu chegar à uma série de conclusões sobre as características adequadas para uma agência reguladora nuclear no Brasil, cujos desdobramentos geraram algumas diretrizes importantes. 
De tal modo, a análise da primeira parte da pesquisa permitiu concluir que:

- Não houve participação efetiva dos servidores da CNEN na proposta de agência elaborada pela gestão;

- A maioria dos servidores quer contribuir para a criação de uma agência reguladora para o setor;

- A maioria dos servidores acredita que deve haver critérios para a ocupação e progressão de cargos na agência reguladora;

- A maioria dos servidores acredita que deve haver tempo máximo de permanência nos cargos;

- Deve existir uma ouvidoria na agência reguladora, mas a participação de membros das associações nessa ouvidoria deverá ser evitada;

- Poucos conhecem a importância da pesquisa regulatória para uma agência reguladora;

- A agência reguladora deve possuir seu próprio laboratório e não contratar um como consultor (TSO);

- A agência reguladora deveria estar subordinada à Casa Civil.

Nesta perspectiva, levando em consideração a análise das respostas enviadas, algumas diretrizes foram incluílas.

Na segunda parte do questionário foram feitas 32 perguntas, no sentido de identificar os pontos fortes e fracos da área de segurança da CNEN (Figuras 3 e 4), de maneira a propor também diretrizes para um melhor funcionamento e transparência de uma futura agência reguladora.

0s resultados tiveram como base o percentual das respostas de todas as perguntas, sendo que uma resposta próxima de 50\% não permite identificar o tópico como um ponto forte ou como um ponto fraco da instituição. Por exemplo, a pergunta P8 obteve respostas sim e não próximas de $50 \%$, portanto, não permite identificar se a pró-atividade dos servidores da CNEN pode ser considerada um ponto forte ou fraco. As opiniões estavam divididas. De tal modo, respostas próximas de 50\% foram consideradas inconclusivas. 


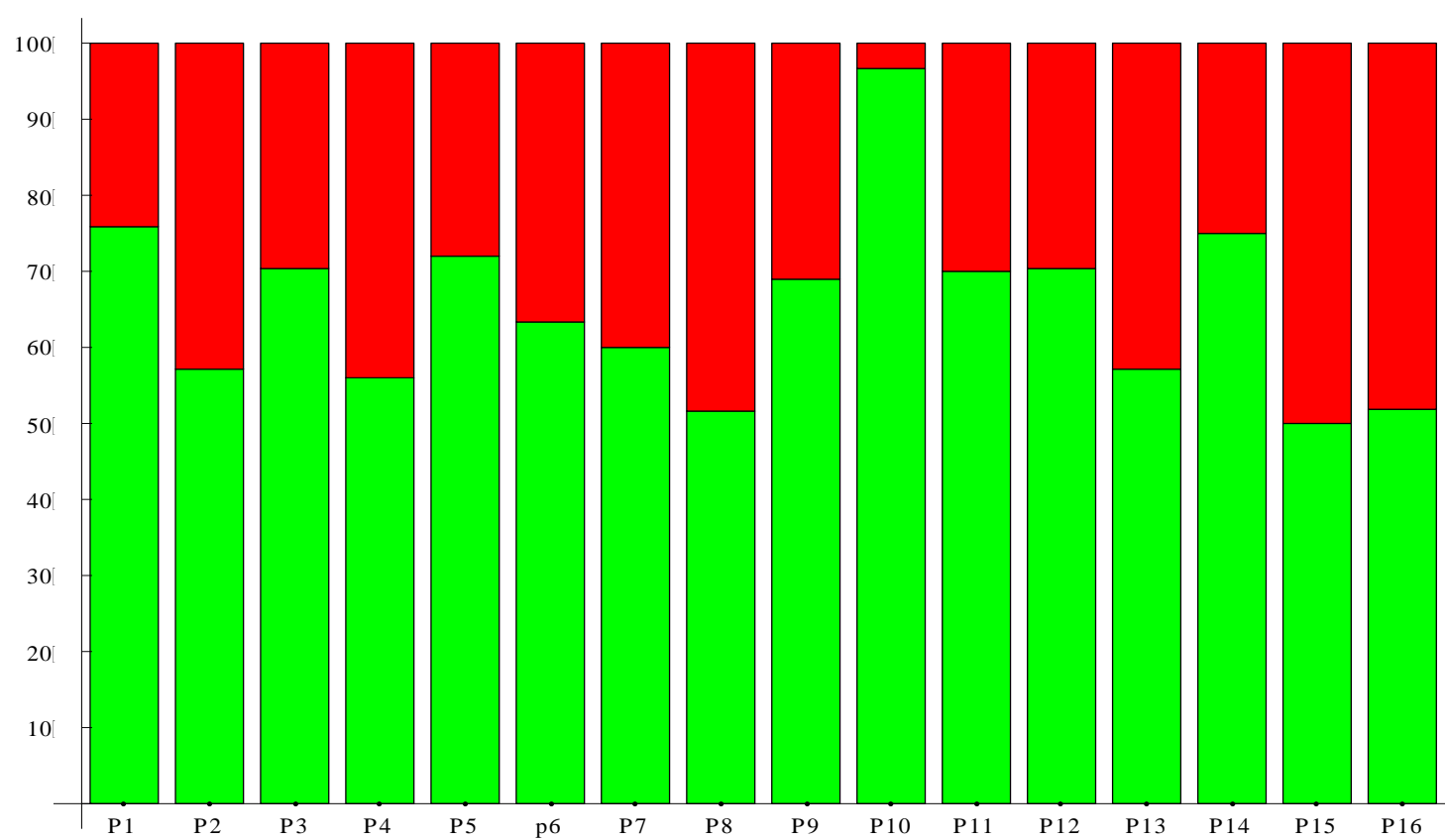

Figura 3. Respostas às perguntas 1 a 16 (verde sim e vermelho não).

Fonte: Figura consolidada pela autora, de acordo com respostas dadas pelos gestores e ex-gestores da CNEN no questionário de pesquisa aplicado.

Observa-se que os pontos de 1 a 7 e 9 a 14 foram considerados pontos fortes pela maioria dos entrevistados,existindo dúvidas com relação aos pontos 8, 15 e 16 (aspectos em amarelo no Quadro 2).

0s resultados abaixo apontam que os pontos 19 a 21 e 24 a 30 foram considerados pontos fracos pela maioria dos servidores. 0 ponto 31 considerado ponto forte e existindo dúvidas com relação aos pontos 17,18, 22, 23 e 32.

É importante observar que os resultados da segunda etapa refletem em parte o resultado da primeira etapa.

A criação de uma Agência Reguladora independente para o setor nuclear vem sendo debatida há muitos anos pela comunidade científica, com o intuito de garantir a separação das duas áreas de atuação da CNEN acima mencionadas.

No Art. $2^{\circ}$ da Lei $n^{0} 7.781$, de 1989 (Brasil, 1989), que estabeleceu as atribuições legais da CNEN, podem ser identificados 18 macroprocessos, dos quais 9 estão relacionados claramente com a área de segurança, 6 exclusivamente com a área de desenvolvimento e 3 permeando essas duas grandes áreas de atuação. 
Quadro 2 - Pontos 1 a 16. Critério de classificação acima de 50\%.

\begin{tabular}{|c|l|}
\hline P0NT0S & \multicolumn{1}{|c|}{ ASPECTOS } \\
\hline P1 & $\begin{array}{l}\text { A DRS atualmente garante a segurança radiológica das instalações nucleares, radiativas, } \\
\text { mínero-industriais }\end{array}$ \\
\hline P2 & $\begin{array}{l}\text { Realização de treinamento com o apoio da AIEA transparente na seleção e indicação de } \\
\text { candidatos }\end{array}$ \\
\hline P3 & Atribuições legais da CNEN definidas claramente \\
\hline P4 & Existência de Memória nas ações de regulação da CNEN \\
\hline P5 & $\begin{array}{l}\text { Representatividade internacional na área de regulação adequada inclusive quanto ao } \\
\text { processo de indicação do representante }\end{array}$ \\
\hline P6 & Interação licenciador - licenciado correta \\
\hline P7 & Incentivo ao Desenvolvimento técnico científico na área regulatória \\
\hline P8 & Pró-atividade dos servidores da CNEN na construção do conhecimento \\
\hline P9 & Apoio institucional da CNEN para a construção do conhecimento do servidor \\
\hline P10 & Respeito aos pareceres técnicos \\
\hline P11 & Ambiente profissional adequado \\
\hline P12 & Transparência na ação reguladora / controladora \\
\hline P13 & Intercâmbio com as principais universidades e outras instituições acadêmicas adequado \\
\hline P14 & Recursos humanos qualificados \\
\hline P15 & Recursos orçamentários adequados \\
\hline P16 & Infraestrutura adequada \\
\hline Fonte \\
\hline
\end{tabular}

Fonte. Quadro consolidado pela autora de acordo com resposta dada pelos gestores e ex-gestores da CNEN no questionário de pesquisa aplicado.

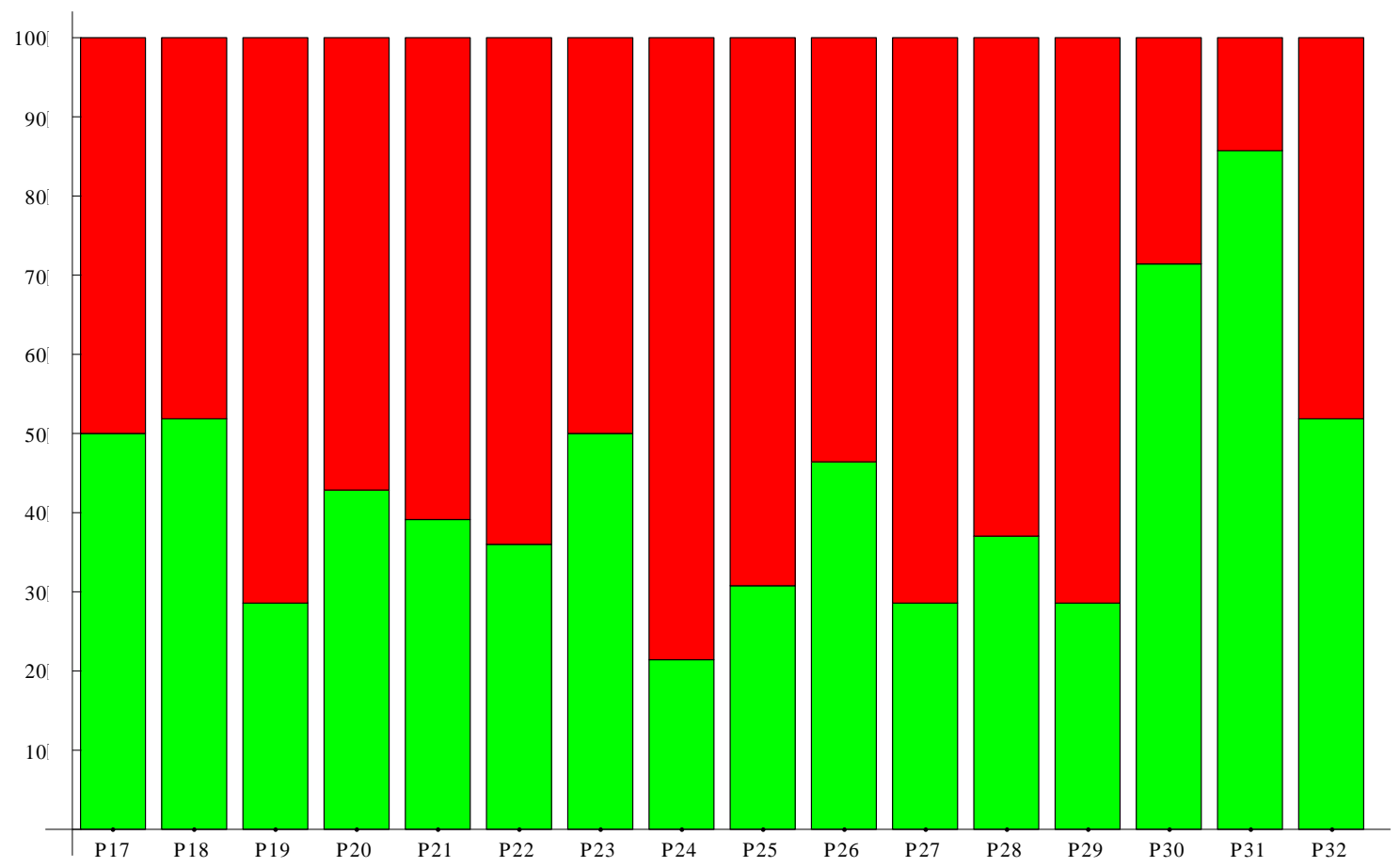

Figura 4. Respostas às perguntas 17 a 32 (verde sim e vermelho não).

Fonte: Figura consolidada pela autora de acordo com resposta dada pelos gestores e ex-gestores da CNEN no questionário de pesquisa aplicado. 
Quadro 3 - Pontos considerados 17-32 - Critério de classificação acima de 50\%.

\begin{tabular}{|l|l|}
\hline P0NT0S & \multicolumn{1}{|c|}{ ASPECTOS } \\
\hline P17 & Número de Escritórios e Distritos suficientes \\
\hline P18 & Número de cargos comissionados adequados \\
\hline P19 & Estrutura organizacional / Regimento interno adequado e respeitado \\
\hline P20 & Plano de cargos e salários adequado \\
\hline P21 & $\begin{array}{l}\text { Sistema Gerencial na DRS (sistema gerencial integrado para acompanhamento do } \\
\text { processo regulatório, processo de gestão - planejamento, avaliação e ações corretivas) } \\
\text { adequado }\end{array}$ \\
\hline P22 & $\begin{array}{l}\text { Programa de formação especializada para recursos humanos nadora } \\
\text { incluindo treinamento adequado }\end{array}$ \\
\hline P23 & Processos de apoio administrativo adequados \\
\hline P24 & Instrumentos de gestão de recursos humanos para aumento da produtividade existentes \\
\hline P25 & Interação entre as Coordenações de forma adequada \\
\hline P26 & Interação entre os servidores de forma adequada \\
\hline P27 & Envolvimento e participação dos servidores nos rumos da instituição \\
\hline P28 & Requisitos para a ocupação de cargos comissionados adequados \\
\hline P29 & Visibilidade / Reconhecimento público da importância das atividades reguladoras \\
\hline P30 & Sobrecarga de trabalho em parte dos servidores \\
\hline P31 & Acesso à documentação técnica adequada (artigos, livros, pareceres, etc) \\
\hline P32 & Sistema de avaliação de servidor de forma adequada \\
\hline
\end{tabular}

Fonte: Quadro consolidado pela autora de acordo com resposta dada pelos gestores e ex-gestores da CNEN no questionário de pesquisa aplicado.

Dentre as áreas comuns, deve ser destacada a condução de pesquisa regulatória que, como abordado mais adiante, deve estar ligada ao órgão regulatório e que, até o presente momento não foi considerada na elaboração de proposta para a criação da agência nuclear. É importante frisar que não se pode confundir pesquisa regulatória com pesquisa básica.

Assim, para a criação de uma agência reguladora nuclear, alguns aspectos precisam ser levados em consideração,entre os quais: a estrutura deve ser baseada nos macroprocessos apontados no Art. $2^{\circ}$ da Lei $n^{0} 7.781 / 1989$; e, refletir a importância da pesquisa regulatória, que é imprescindível para a avaliação de critérios normativos e para o desenvolvimento seguro de modelos de avaliação de segurança nuclear e radiológica, até então não considerados no anteprojeto.

Além disso, faz-se necessário manter uma estrutura técnica e administrativa eficiente e enxuta que leve em consideração esses principais macroprocessos e os recursos humanos necessários para a condução dos trabalhos. Do mesmo modo, deve-se, também, incorporar nas 
discussões as unidades independentes (como por exemplo, universidades) que possam apoiar as atividades de licenciamento e controle.

Todos esses fatos apontam para a necessidade de se propor uma solução definitiva para efetivar a separação da CNEN, cuja solução atualmente existente não é única, como mostrado a seguir:

1. Retirar o controle da CNEN das unidades de produção de radionuclídeos (OS), bem como a INB e NUCLEP, permanecendo a CNEN apenas com as áreas de segurança, pesquisa regulatória e calibração, além dos necessários laboratórios/institutos para análise ambiental independente;

2. Criar uma agência reguladora formada pela área de segurança e proteção radiológica da CNEN, incluindo os Distritos e Escritórios Regionais, e apoiada pelo LAPOC (Laboratório de Poços de Caldas) e pelo IRD(Instituto de Radioproteção e Dosimetria), unidades onde seriam realizadas as necessárias atividades de pesquisa regulatória, análises radiométricas, calibração de detectores de radiação e apoio ao licenciamento, permanecendo a CNEN com suas demais unidades.

Alguns dos pontos supracitados foram levantados pelo próprio Ministério do Planejamento Orçamento e Gestão, em sua nota técnica Nº 328/2013-DEPEF/SEGEP/MP (itens 12-17) (MP0G, 2013).

Além do mais, conforme mostrado anteriormente, existemdiferentes possibilidades para a formação de uma agência reguladora do setor nuclear, além do que, a dimensão da mesma (independente do melhor modelo a ser adotado), incluindo na sua estrutura, recursos humanos e financeiros, depende fortemente da extensão do programa nuclear brasileiro a ser adotado nos próximos anos e do modelo final escolhido.

Assim, independente de qual alternativa seja escolhida, é preciso ressaltar os seguintes aspectos:

1. A importância de tratar o processo como um todo, ou seja, a reestruturação da área nuclear no espaço organizacional do MCTIC;

2. A recomendação de se rever o projeto de lei da Agência Nacional de Segurança Nuclear, em função de novas premissas e das legislações envolvidas; 
3. A recomendação de que todo o processo de reestruturação seja realizado com ampla participação de todos os atores envolvidos.

Face ao acima exposto e tendo como base as discussões anteriores, recomenda-se que a proposta de criação da agência reguladora nuclear seja revista, levando-se em conta, entre outros aspectos importantes, as seguintes propostas de diretrizes:

1. Divulgar a proposta que for revisada para a agência reguladora,tornando-a disponível para comentários por todos os servidores, de maneira a garantir uma maior participação, como desejam os servidores;

2. A importância da pesquisa regulatória para a área de segurança de uma agência reguladora nuclear deve estar refletida no projeto de agência, incluindo a necessidade da formação de mestres e doutores para conduzir pesquisas voltadas às necessidades de regulação no campo nuclear e para compor os quadros da agência reguladora;

3. Recomenda-se muito cuidado com a seleção de "Organizações de Suporte Técnico" (TSO, em inglês) pela agência reguladora, de maneira a evitar conflitos de interesses, isto é, organizações que de alguma forma são licenciadas ou controladas pela autoridade regulatória não devem servir de TSO.Recomenda-se, portanto, evitar o apoio de institutos de pesquisa nucleares da CNEN como TS0 em uma futura agência reguladora do setor nuclear. Recomenda-se dar preferência à universidades e órgãos regulatórios internacionais para contratação como TSO, de maneira a manter uma efetiva independência entre o órgão regulador e operador;

4. Recomenda-se estabelecer no Projeto de Lei da agência reguladora critérios mínimos de conhecimento técnico-científico e de experiência para ocupação e progressão nos cargos. Também, deve-se criar tempo máximo de permanência em cada cargo, permitindo a oxigenação dos mesmos e que sirva de incentivo para os servidores;

5. Recomenda-se que a agência possua um ou mais laboratórios, tais como o IRD e o LAPOC, para que sejam feitas as análises ambientais de forma independente;

6. Recomenda-se que a agência reguladora incorpore em sua estrutura uma ouvidoria. Recomenda-se que sua composição seja feita sem representantes das associações;

7. Recomenda-se estabelecer um plano claro e critérios técnicos para ocupação, permanência e progressão nos cargos, conforme apontado na análise do primeiro questionário; 
8. Recomenda-se que o regime de trabalho dos servidores da agência seja o RJU (Regime Jurídico Único);

9. Recomenda-se desenvolver um programa de treinamento adequado para os servidores da agência e isso deve estar refletido em sua estrutura. (Deve haver um departamento seriamente comprometido com o treinamento e a gestão do conhecimento);

10. 0 projeto da agência reguladora deve ser discutido com a sociedade científica (entre elas a ABC (Academia Brasileira de Ciências), a COPPE (Instituto Alberto Luiz Coimbra de Pós-Graduação e Pesquisa de Engenharia), etc) e não fechado a um grupo da CNEN, como foi feito anteriormente;

11. Recomenda-se que seja feita uma discussão de forma clara e transparente quanto ao número ideal de cargos, em função dos macroprocessos e do tamanho futuro do programa nuclear brasileiro;

12. É necessário valorizar a titulação (mestres e doutores) no plano de cargos e salários, posto que muitos dos modelos necessários à avaliação de segurança das instalações nucleares, radiativas, minero-industriais e de depósitos de rejeitos, são desenvolvidos pelos próprios técnicos da área;

13. É necessário valorizar a pesquisa regulatória na agência reguladora brasileira,à semelhança do que existe no mundo, como nos EUA (NRC e EPA), na França (ISPN), entre outros, de maneira a garantir modelos seguros, verificados e validados nas avaliações, bem como evitar as chamadas "barreiras não alfandegárias" e garantir que o sistema normativo nuclear brasileiro seja coerente. Também é importante incluir o LAPOC ou IRD, ou ambos na estrutura da agência;

14. Recomenda-se que no projeto de criação da agência, sua estrutura seja rapidamente definida, juntamente com critérios técnicos e claros para ocupação e progressão nos cargos;

15. Discutir de forma mais aprofundada a questão das multas, não apenas em termos de valores, mas também sobre o devido processo legal de sua aplicação, o que demandaria a participação da Procuradoria Federal da CNEN;

Avaliar todas as Leis (por exemplo: Lei das taxas, Lei de rejeito, Lei relacionada com o controle de estoque, Lei de Responsabilidade Civil, Lei de Crime Ambiental, Lei de criação da CNEN e suas modificações, etc.) relacionadas com o programa nuclear brasileiro para verificar as mudanças necessárias, que seria função do tipo de modelo escolhido para a agência reguladora, não incluído no anteprojeto enviado ao MCTIC. 


\section{CONCLUSÃ0}

0 presente trabalho teve como objetivo geral propor diretrizes para a criação de uma agência reguladora do setor nuclear no Brasil, em consonância com as exigências de uma sociedade moderna. Ao todo, 16 diretrizes foram propostas neste artigo, visando o aprimoramento de uma agência reguladora nuclear e tendo como base a análise das respostas dos questionários aplicados aos gestores e ex-gestores experientes da CNEN.

\section{REFERÊNCIAS BIBLIOGRÁFICAS}

ARAƯJO, C. H. GPIRES, J. C. L. Economia da Regulação: Fundamentos e Experiência Brasileira. Rio de Janeiro, 2001.

BARROSO, L. R. Natureza Jurídica e funções das agências reguladoras de serviços públicos. Limites da Fiscalização a ser desempenhada pelo Tribunal de Contas do Estado. Boletim de Direito Administrativo, São Paulo, 1999.

BRASIL. CF/88.Constituição da República Federativa do Brasil de 1988. 1988.

BRASIL. DECRET0 n ${ }^{0}$ 2.648, de $1^{0}$ de julho de 1998. Promulga o Protocolo da Convenção de Segurança Nuclear, assinado em Viena, em 20 de setembro de 1994. 1998.

BRASIL. LEI FEDERAL n ${ }^{0} 7.781$, de 27 de junho de 1989 - Dá nova redação aos artigos $2^{\circ}$, 10 e 19 da Lei º 6.189, de 16 de dezembro de 1974, e dá outras providências. 1989.

BRASIL. RELATÓRIO DO GRUPO DE TRABALHO DE FISCALIZAÇÃ0 E SEGURANÇA NUCLEAR - Câmara dos Deputados Comissão de Meio Ambiente e Desenvolvimento Sustentável - Relator: Deputado Edson Duarte. Brasília. 2006.

BRESSER PEREIRA, L. C.A Reforma do Estado dos anos 90: Lógica e mecanismos de controle, MARE (Ministério da Administração Federal e Reforma do Estado). Caderno MARE da Reforma do Estado, 1997.

CLARK, G. Política econômica e Estado. Revista Scientia Iuris: Revista do Curso de Mestrado em Direito Negocial da UEL, Londrina: Editora da UEL, v. 11, p. 73-83, jul./dez. 2007.

CNEN - COMISSÃO NACIONAL DE ENERGIA NUCLEAR. Disponível em: 〈http://www.cnen.gov.br . Acesso em: 02 set. 2016.

CRUZ, J.B. Democracia e Estado Regulador - 0 Caso das Agências Reguladoras no Direito Brasileiro. Revista da AJURIS, v. 39 - nº 126 - junho/2012.

DIAS, L. N. 0 papel das agências reguladoras no Brasil. Monografia, Faculdades Integradas "Antonio Eufrásio de Toledo"-2010. Disponível em:

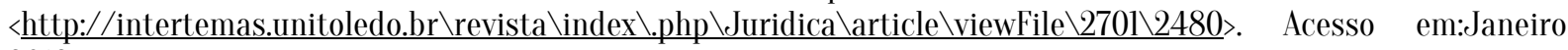
2016.

MESQUITA, M. S. M.0 reforço da legitimidade democrática das Agências Reguladoras, 2008.

MPOG - MINISTÉRI0 DO PLANEJAMENT0 E GESTÃ0. Nota técnica nº 328/2013-DEPEF/SEGEP/MP (itens 12-17), 2013. 
FÉ, C. F. C. D. M. Agências reguladoras e reforma do estado brasileiro: insulamento burocrático ou democratização do estado? Um estudo multicaso (ANEEL, ANATEL, ANVISA e ANS). Dissertação (Mestrado em Gestão Empresarial).Escola Brasileira de Administração Pública da Fundação Getúlio Vargas (EBAP/FGV). 2003.

NUNES, A.J.A. Breve reflexão sobre o chamado Estado Regulador. Sequência - Revista do Curso de Pós-Graduação em Direito da Universidade Federal de Santa Catarina (UFSC), Florianópolis: Fundação Boiteux, a. XXVII, n. 54, p. 0918, jul. 2007.

PACHECO, R.S. Regulação no Brasil: desenho das agências e formas de controle. RAP - Revista de Administração Pública, Rio de Janeiro: Editora FGV, v. 40, n. 4, p. 523-543, jul./ago. 2006.

PECI, A. \& Cavalcanti, B. S.Reflexões sobre a autonomia do órgão regulador: análise das agências reguladoras estaduais. Revista de Administração Pública, 34.5, p. 99-118, 2000. 